Special Issue of the 7th International Advances in Applied Physics and Materials Science (APMAS 2017)

\title{
Tribological Behavior of Borided Ti6Al4V Alloy under Simulated Body Fluid Conditions
}

\begin{abstract}
Y. KAPLAN AND A. IŞITAN*
Pamukkale University, Faculty of Technology, Department of Manufacturing Engineering, Denizli, Turkey

Ti6Al4V alloy is the most widely used titanium alloy due to its attractive properties such as heat resistance, strength, plasticity, toughness, formability, weld-ability, corrosion resistance and biocompatibility. However, the main problem with titanium and its alloys is that they have poor tribological performance. Boriding seems to be the effective way to improve the tribological performance of titanium alloys. Titanium borides have an attractive combination of low density, high hardness, excellent wear, and corrosion resistance. In this study, Ti6Al4V alloy was borided in a solid media at $1100{ }^{\circ} \mathrm{C}$ for $20 \mathrm{~h}$. The microhardness profile was studied by a Vickers indenter. The hardness value of surface increases from $330 \mathrm{HV}$ to $2789 \mathrm{HV}$. Wear experiments were performed in Ringer's solution that simulates human body environment. It was observed that boriding process improved tribological performance of Ti6Al4V alloy under all test conditions.
\end{abstract}

DOI: 10.12693/APhysPolA.134.271

PACS/topics: boriding, Ti6Al4V, simulated body fluid, wear, volume loss

\section{Introduction}

The first Ti6Al4V alloy was successfully produced in 1954 in the United States. Ti6Al4V alloy is provided with heat resistance, strength, plasticity, toughness, formability, weld-ability, corrosion resistance and biocompatibility, so it has been widely used in various fields. Many other titanium alloys can be regarded as modified $\mathrm{Ti}_{-}^{-}$ $6 \mathrm{Al}-4 \mathrm{~V}$ alloy. At present, hundreds of kinds of titanium alloys have been developed in the world, and the most famous alloys consist of 20-30 types. Ti6Al4V titanium alloy's consumption accounted for the $75-85 \%$ among all kinds of titanium alloys [1-3].

Titanium and its alloys are widely used in many biomedical applications, areas of aerospace, marine, chemical, power and automotive industries etc. Aerospace applications account for $80 \%$ of that usage, its level of use in chemical, petrochemical, and sports applications is increasing. Although densities of aluminum $\left(2.7 \mathrm{~g} / \mathrm{cm}^{3}\right)$ and magnesium $\left(1.7 \mathrm{~g} / \mathrm{cm}^{3}\right)$ are wellknown, density of titanium, which is relatively less-known $\left(4.5 \mathrm{~g} / \mathrm{cm}^{3}\right)$, is approximately $60 \%$ of iron. However, it does not seem possible to replace steels and other hard metals for contact and wear-resistant applications where high surface hardness and wear resistance are required. The main problem with titanium and its alloys is that their poor tribological performance properties limit their applications in related industries $[4,5]$.

Surface modification seems to be the effective way to improve the tribological performance of titanium alloys. Ceramic coatings could improve the surface properties. Especially, TiN, TiC, TiB and TiB2 ceramics have an attractive combination of low density, high hardness, ex- cellent wear resistance and corrosion resistance. Titanium borides are well-known for their high hardness and excellent wear resistance in many tribological systems. These characteristics make boronizing an excellent candidate for surface modification of titanium alloys [6-11].

In this study, solid boronizing method was used to boronize Ti6Al4V alloy and wear behavior of boronized Ti6Al4V alloy was investigated through a series of experiments.

\section{Materials and method \\ 2.1. Boriding of Ti6Al4 V alloy}

Ti6Al4V alloy which widely used in many biomedical application was boronized in a solid media which is the mixture of $\mathrm{B}_{4} \mathrm{C}, \mathrm{KBF}_{4}$ and $\mathrm{Al}$ at $1100^{\circ} \mathrm{C}$ for $20 \mathrm{~h}$. After boronizing process, specimens were grinded with 100 , 240, 400, 800, 1000 and 1200 grids of $\mathrm{SiC}$ papers. The section was then polished via a $6 \mu \mathrm{m}$ diamond paste followed by a $3 \mu \mathrm{m}$ diamond paste. Finally, $1 \mu \mathrm{m}$ alumina was applied at the end of the polishing process. After polishing, the samples were etched with Kroll's reagent. The chemical composition of Ti6Al4V alloy is shown in Table I. The thickness of borided layers was investigated by scanning electron microscope (SEM). X-ray diffraction (XRD) was used to determine the elements of coating.

Chemical composition of Ti6Al4V alloy (wt\%)

TABLE I

\begin{tabular}{c|c|c|c}
\hline \hline $\mathrm{Al}$ & $\mathrm{C}$ & $\mathrm{H}$ & $\mathrm{F}$ \\
\hline $5.5-6.5$ & $<0.08$ & $<0.015$ & $<0.3$ \\
\hline \hline $\mathrm{O}$ & $\mathrm{N}$ & $\mathrm{V}$ & $\mathrm{Ti}$ \\
\hline$<0.2$ & $<0.05$ & $3.5-4.5$ & balance
\end{tabular}




\subsection{Hardness and wear tests of borided Ti6Al4 $V$ alloy}

The wear tests were carried out in accordance with ASTM standard G99 using a pin-on-disc configuration under dry and simulated body fluid (SBF) conditions. G99 standard test method explains how to carry out wear testing with a pin-on-disk apparatus. Two specimens are required for the pin-on-disk wear test. One of this is a pin with a radiused tip, is positioned perpendicular to the other, usually a flat circular disk. The pin specimen is pressed against the disk at a specified load usually by means of an arm or lever and attached weights. Wear results are reported as volume loss in cubic millimeters [12]. Specimens from Ti6Al4V cylinder have been used as $\phi 10 \times 25 \mathrm{~mm}^{2}$ pins, while AISI 52100 material has been used on also $\phi 60 \times 16 \mathrm{~mm}^{2}$ disks. The hardness of disk material has been determined to be $60 \mathrm{HRC}$ at the end of the quenching in oil after austenitizing.

Wear test apparatus is shown in Fig. 1. Wear tests were performed at $2 \mathrm{~m} / \mathrm{s}$ constant sliding speed. Experiments were performed applying three different loads (100, 200, and $300 \mathrm{~N}$ ) at three different sliding distances (600, 900, and $1200 \mathrm{~m}$ ) under dry and SBF. In literature, Ringer's solution has been used for simulating human body environment of orthopedic implants. In experimental study, Ringer's solution was preferred as SBF under wet sliding conditions. Composition of the Ringer's solution is given in Table II.

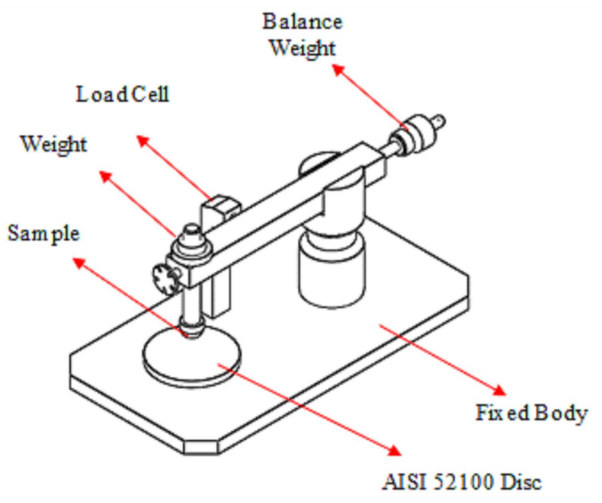

Fig. 1. Schematic illustration of wear test apparatus.

Composition of Ringer's solution

TABLE II

\begin{tabular}{l|c}
\hline \hline Composition & Weight \\
\hline distilled water & $100 \mathrm{ml}$ \\
$\mathrm{NaCl}$ & $0.86 \mathrm{~g}$ \\
$\mathrm{CaCl}_{2} .2 \mathrm{H}_{2} \mathrm{O}$ & $0.033 \mathrm{~g}$ \\
$\mathrm{KCl}$ & $0.03 \mathrm{~g}$
\end{tabular}

\section{Results and discussion}

\subsection{Microstructure of boronized Ti6Al4 $V$ alloy}

Metallographic cross-section of boronized Ti6Al4V alloy and XRD pattern is shown in Fig. 2. The SEM image of borided Ti6Al4V alloy shows that two-phase boride layer was produced on Ti6Al4V surface during solid boriding process. XRD pattern confirmed the presence of $\mathrm{TiB}$ and $\mathrm{TiB}_{2}$ phases on surface of Ti6Al4V alloy. The obtained boride layer had a thickness of approximately $15 \mu \mathrm{m}$.
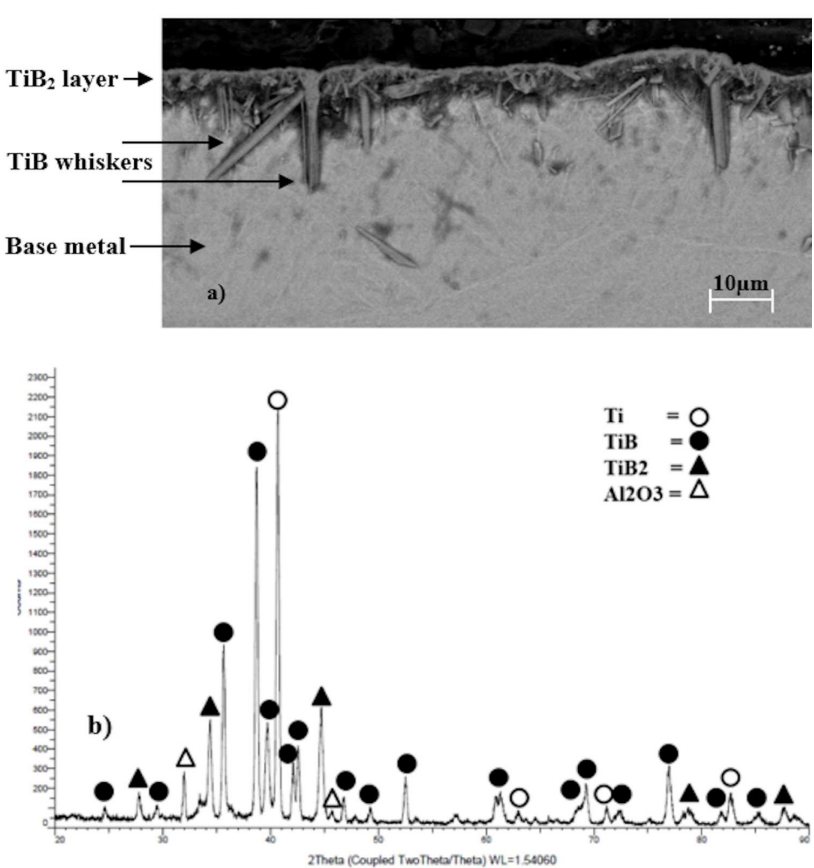

Fig. 2. SEM image (a) and XRD pattern (b) of boronized Ti6Al4V alloy.

\subsection{Hardness and wear behavior of borided Ti6Al4 $\mathrm{V}$ alloy}

The microhardness from surface to interior of specimen was measured by a standard Vickers microhardness tester under $50 \mathrm{~g}$ load. Microhardness profile of boronized Ti6Al4V is given in Fig. 3. The hardness of untreated Ti6Al4V is approximately $330 \mathrm{HV}$. The hardness value increased to $2789 \mathrm{HV}$ after boronizing process. The highest hardness was obtained at top of boronized Ti6Al4V surface. The boron diffusion zone was measured to be approximately $250 \mu \mathrm{m}$.

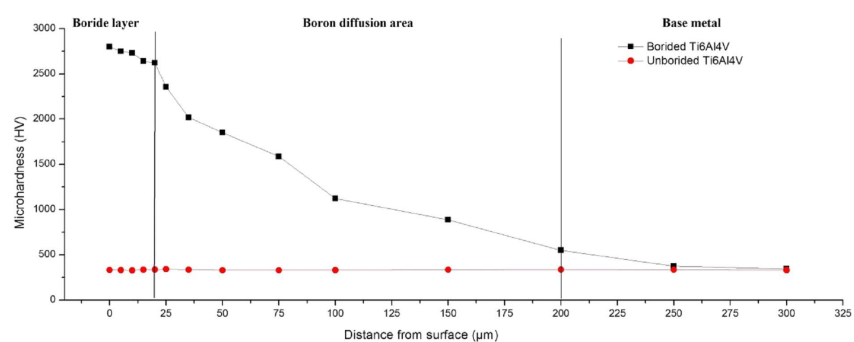

Fig. 3. Microhardness profile of boronized Ti6Al4V. 
Figures 4-6 present wear behavior of unborided and borided Ti6Al4V under SBF and dry sliding conditions. Figure 4 shows that SBF causes more volume loss on unborided Ti6Al4V alloy than dry sliding conditions under all test parameters. Titanium and its alloys are considered to have poor oxidative wear resistance when "tribochemical" reactions occur at the contact area [13]. It has been reported that corrosion is an accelerating factor on the wear behavior on these alloys [14]. Apart from its lubricating action, SBF may also cause electrochemical reaction on the surface of the titanium alloy which can accelerate volume loss. These results indicate that the tribological factors in the body are different than out of body. In other words, implants contact body fluid can be exposed more wear than implants used outside of the body. In addition, volume loss was increased with increasing sliding distance.

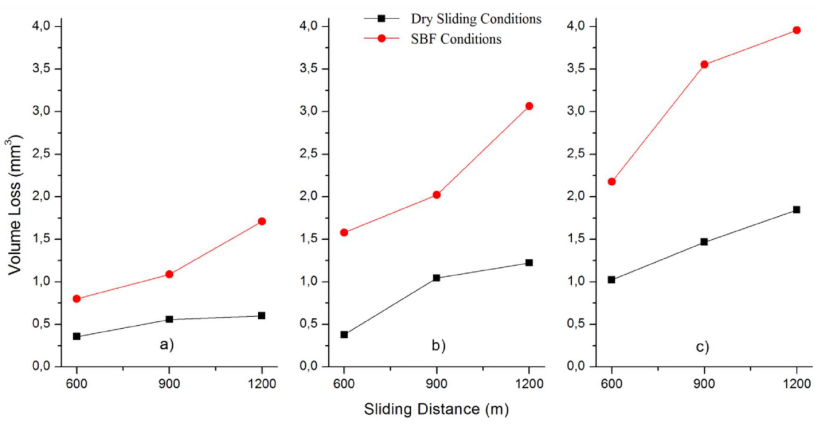

Fig. 4. Volume loss of unborided Ti6Al4V under SBF conditions: (a) $10 \mathrm{~N}$, (b) $20 \mathrm{~N}$, (c) $30 \mathrm{~N}$.

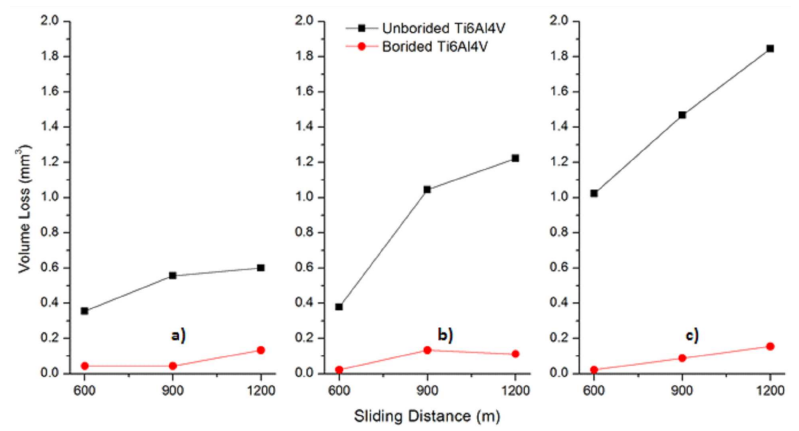

Fig. 5. Volume loss of borided and unborided Ti6Al4V under dry sliding conditions: (a) $10 \mathrm{~N}$, (b) $20 \mathrm{~N}$, (c) $30 \mathrm{~N}$.

As can be seen in Fig. 5, boronized Ti6Al4V alloy was worn less than unborided Ti6Al4V alloy under all tests parameters for dry sliding conditions. The highest volume loss was obtained approximately as $0.15 \mathrm{~mm}^{3}$ for borided Ti6Al4V and $1.9 \mathrm{~mm}^{3}$ for untreated Ti6Al4V under $30 \mathrm{~N}$ load and $1200 \mathrm{~m}$ sliding distance parameters. Consequently, borided alloy has higher wear resistance approximately 13 times than the unborided alloy under these conditions.
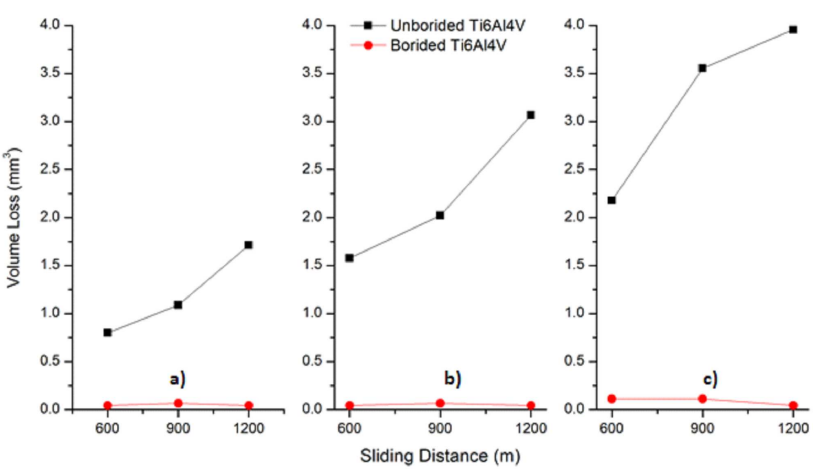

Fig. 6. Volume loss of borided and unborided Ti6Al4V under SBF conditions: (a) $10 \mathrm{~N}$, (b) $20 \mathrm{~N}$, (c) $30 \mathrm{~N}$.

Wear behavior of borided and unborided Ti6Al4V under SBF conditions can be shown in Fig. 6. Volume loss of borided alloy was decreased under all test parameters. Moreover, SBF cause higher volume loss, approximately 36 times, on unborided alloy than borided alloy. By comparison with volume loss of wear experiments, borided Ti6Al4V alloy acts in same manner for all test parameters. During wear tests, only top surface of boronized Ti6Al4V has $2789 \mathrm{HV}$ hardness contacts counter disk and this hard layer could not be removed in wear experiments for all test parameters. Therefore, volume loss of boronized alloy was obtained similar under all conditions.

\section{Conclusion}

This study investigated that hard ceramic coating obtained by boronizing process significantly decreases the level of wear of the Ti6Al4V alloy. SEM images and XRD patterns confirmed the presence of $\mathrm{TiB}$ and $\mathrm{TiB}_{2}$ phases on the surface of Ti6Al4V alloy. Besides, hardness of surface has increased from $330 \mathrm{HV}$ to $2789 \mathrm{HV}$ after boronizing process. The wear resistance of boronized Ti6Al4V alloy is higher than untreated Ti6Al4V alloy. When compared with the dry and SBF conditions, SBF causes higher volume loss for unborided Ti6Al4V alloy. In other words, implants contact body fluid can be exposed for more abrasion than implants used outside of the body. It is understood that boronized Ti6Al4V alloy may be an excellent candidate for tribological systems.

\section{Acknowledgments}

This study was supported by the Scientific Research Department of Pamukkale University via project 2014FBE046.

\section{References}

[1] O.M. Ivasyshyn, A.V. Aleksandrov, Mater. Sci. 44 311 (2008).

[2] M. Gonzalez, K. Maskos, R. Hargrave, J. Kuberry, Soc. Petrol. Eng. 3, 1912, (2008).

[3] M. Kearns, Adv. Mater. Process. 163, 63 (2005). 
[4] L. Fenghua, Y. Xiaohong, Z. Jinglei, F. Zhanguo, G. Dianting, X. Zhengping, Acta Metall. Sin. 23, 293 (2010).

[5] K.E. Budinski, Wear 151, 203 (1991).

[6] E. Rodriguez Cabeo, G. Laudien, S. Biemer, K.T. Rie, S. Hoppe, Surf. Coat. Technol. 116-119, 229 (1999).

[7] E.C. Rodriguez, G. Laudien, S. Biemer, K.T. Rie, S. Hoppe, M. Frick, Harter Tech. Mitt. 54, 110 (1999).

[8] C. Badini, M. Bianco, S. Talentino, X.B. Guo, C. Gianoglio, Appl. Surf. Sci. 54, 374 (1992).
[9] H. Krzyminski, Harter Tech. Mitt. 28, 100 (1973).

[10] H. Kunst, Harter Tech. Mitt. 28, 105 (1973).

[11] P. Kaestner, J. Olfe, K.T. Riea, Surf. Coat. Technol. 142-144, 248 (2001)

[12] ASTM G99-17"Standard test method for wear testing with a pin-on-disk apparatus" (2017).

[13] P. Majumdar, S.B. Singh, M. Chakraborty, Wear 264, 1015 (2008)

[14] G. Manivasagam, U.K. Mudali, R. Asokamani, B. Raj, Corros. Rev. 21, 125 (2003). 